Available online at GSC Online Press Directory

GSC Biological and Pharmaceutical Sciences

e-ISSN: 2581-3250, CODEN (USA): GBPSC2

Journal homepage: https://www.gsconlinepress.com/journals/gscbps

(RESEARCH ARTICLE)

\title{
Renal architectural changes in Plasmodium berghei inoculated mice
}

\author{
Omoirri MA ${ }^{1}$, Madubogwu NU 2, Iloh SE ${ }^{2}$, Adejumo SA ${ }^{3}$ and Ojiako $\mathrm{CM}^{3}$ \\ ${ }^{1}$ Department of Pharmacology and Toxicology, Faculty of Pharmaceutical Sciences, Nnamdi Azikiwe University, Akwa, \\ Anambra State, Nigeria.
}

${ }^{2}$ Department of Pharmacology and Toxicology, Chukwuemeka Odumegu University, Igbariam, Anambra State, Nigeria.

${ }^{3}$ Department of Pharmaceutical Microbiology and Biotechnology, Nnamdi Azikiwe University, Awka, Anambra State, Nigeria.

Publication history: Received on 13 November 2020; revised on 20 December 2020; accepted on 22 December 2020

Article DOI: https://doi.org/10.30574/gscbps.2020.13.3.0409

\begin{abstract}
Plasmodium falciparum (P. falciparum) is a specie of Plasmodium parasite responsible for the pathogenicity of malaria, a disease with several complications reported as the leading cause of over 1 million deaths worldwide. In this study, the effects of malaria on the kidney (Renal) histo-architecture was studied ex-vivo in albino mice rats. Twenty one (21) albino mice rats of between 30 - 35g weights were procured, acclimatized for two weeks in the animal unit of the Ambrose Alli University, Ekpoma, Edo State. They were then grouped into three (3) of seven (7) mice each, following which group I received standard rat diet and water ad libitum (control). Using the $2 \mathrm{ml}$ syringe, Groups II and III were inoculated with $0.2 \mathrm{ml}$ of the malaria parasite Plasmodium berghei each intra-peritoneally. While group II mice were left untreated for 7 days, group III (infested) mice were administered with $5.7 \mathrm{mg} / \mathrm{kg}$ body weight of Coartem (an antimalaria), morning and evening for 1 week. Following period of administration of substances, kidneys were harvested, rid of adherent tissues, and subjected through histological scrutiny to ascertain the changes in renal histo-morphology across groups. For each group, body weight changes were also noted within test duration and compared between groups with the one way analysis of variance. Where differences exist, the tukey (Post Hoc) test was used to ascertain the cause of the differences in body weight due to P. berghei. From the result, a statistically significant decrease $(p>0.05)$ in body weight was observed in P. berghei infested mice (Groups II and II) compared with control (group I). Body weight however recovered in Group III mice treated with coartem, proving to have increased significantly $(\mathrm{p}<0.05)$ compared to control group. Renal histo-architectural changes revealed glomerulosclerosis, interstitial oedema and congested vessels in group II mice compared to control. We recommend similar study in other tissues other than the kidney for reference purposes
\end{abstract}

Keywords: Kidney; Malaria; P. berghei; Renal Histo-architecture

\section{Introduction}

The kidneys are pair bean-shaped organs in all vertebrates, and are located at the back of abdominal cavity, one on each side of spine [1]. Due to the asymmetry caused by the liver the left kidney is slightly smaller than the right. In humans, each kidney weighs between 125-170 grams in males and 115-155 grams in females [2]. Inside the kidneys are numbers of pyramid shaped tubes, each consist of an outer- renal cortex and inner renal medulla. Following between these

\footnotetext{
${ }^{*}$ Corresponding author: MA Omoirri

Department of Pharmacology and Toxicology, Faculty of Pharmaceutical Sciences, Nnamdi Azikiwe University, Akwa, Anambra State, Nigeria.
}

Copyright (C) 2020 Author(s) retain the copyright of this article. This article is published under the terms of the Creative Commons Attribution Liscense 4.0. 
sections are nephrons, the urine producing structure of kidneys [1]. Blood enters the kidney through the renal veins. The kidneys are relatively small organs, but they received up to $25 \%$ of hearts outputs [3]. They are vital life sustaining organs, performing many functions to keep the blood clean and chemically balance (America Kidney Fund, 2014). Several diseases have been reported to affect the functionality of the kidney. Common of these is malaria [4].

Malaria is transmitted through the bite of an infected female Anopheles mosquito (Barat, 2006; WHO, 2012). Malaria parasite can also be transmitted through blood transfusion, although this is rare [5]. The life cycle of this parasite is complex, requiring an insect vector and a human host. There are three phases in this life cycle; pre-erythrocytic cycle, the erythrocytic cycle and the sporogonic cycle. The parasite infects the liver hepatocytes after being injected into the blood stream by a bite of an infected female Anopheles mosquito. Following a short period of development and multiplication, these parasites leave the liver and invade the red blood cell (erythrocytes). The multiplication of the parasite in the blood causes pathology such as anaemia and damage of essential organs of the host such as lungs, liver, spleen and brain.

Plasmodium berghei is a unicellular parasite (protozoan) and it infects mammals other than humans. P. berghei is one of the four Plasmodium species that have been described in African marine rodents. P. berghei is used as a model organism for the investigation of human malaria due to its ability to infect rodents and its similarity to the Plasmodium species which cause malaria in humans [6]. P. berghei has a very similar life-cycle to the species that infect humans, and it causes disease in mice which has signs similar to those seen in human malaria. Importantly, P. berghei can be genetically engineered more easily than other species which infect humans, making it a useful model for research into Plasmodium genetics and research.

Available reports have clearly associated malaria with glomerular diseases in tropical areas [2]. Severe malaria has been implicated to cause disease in glomeruli, tubules and in the interstitial region. Kidney disease in malaria has also primarily been reported to be the result of erythrocyte abnormalities. Parasitized red cells (for instance) are known to adhere to healthy erythrocytes, blood platelets and capillary endothelium, leading to formation of rosettes and clumps, which impair microcirculation [3], and these events are probable contributing factors for kidney injury, in association with hemodynamic instability, including hypovolemia and shock.

Several factors contribute to the occurrence of these complications, including hypovolemia, vasoconstriction, hemolysis (leading to hemoglobinuria), erythrocyte parasitemia, immune complexes deposition in glomeruli, microcirculation dysfunction (due to cytoadherence of parasite erythrocytes) and rhabdomyolysis (which is not common in malaria). Other contributing factor for kidney disease in malaria is hepatic dysfunction, with jaundice and hepatomegaly, through which hyperbilirubinemia can lead to cast nephropathy and acute kidney injury (AKI), and liver disease and its complications can also cause AKI (hepato-renal syndrome)[4].

Despite decades of research, malaria infection remains a major global health problem with high mortality in tropical regions. Statistics in Nigeria has shown that malaria causes mortality in $25 \%$ of children under-five years, $30 \%$ of childhood and $11 \%$ in mothers [7]. All Nigerians are at great danger of malaria infection daily and the mayhem is worsened by the resistance of malaria to anti-malaria drugs. To this point, administration of antimalaria treatment has drawn serious attention $[8,9]$. However, as part of its mechanism of action, these drugs reportedly generate antioxidant species to scavenge free radicals resulting from organ/tissue breakdown. Since there are still conflicting evidences on the matter, it was therefore important to attempt clarification; justifying the need for current study.

\subsection{Aim of Study}

This study investigated Renal-Architectural changes in Plasmodium berghei inoculated mice. Specifically, study;

- $\quad$ Determined the effect of $P$. berghei induced malaria on body weights

- Determined the effects of Malaria on the histo-architecture of the kidney

- Ascertain the possible mechanism of action of coartem in P. berghei inoculated mice

\section{Material and methods}

\subsection{Study Area}

This study was carried out in the Department of Human Physiology, Faculty of Basic Medical Sciences, College of Medicine, Ambrose Alli University, Ekpoma, Edo State, Nigeria. 


\subsection{Animals Procurement and Acclimatization}

A total of twenty one (21) adult male albino mice of an average weight of about between $160 \mathrm{~g}$ - $200 \mathrm{~g}$ were procured, housed and acclimatized (for two weeks) in the animal house of the study institution.

\subsection{Study Design}

Following period of acclimatization, Animals were then grouped into three (3) of seven (7) mice each, following which group I received standard rat diet and water ad libitum (control). Using the $2 \mathrm{ml}$ syringe, Groups II and III were inoculated with $0.2 \mathrm{ml}$ of the malaria parasite Plasmodium berghei each intra-peritoneally. While group II mice were left untreated for 7 days, group III infested mice were administered with $5.7 \mathrm{mg} / \mathrm{kg}$ body weight of Coartem (an antimalaria), morning and evening for 1 week

\subsection{Inoculation with Plasmodium berghei}

Four (4) Plasmodium berghei infected mice (donor) were obtained from the Nigerian Institute of Medical Research (NIMR) Yaba, Lagos, Nigeria, and were used to inoculate the experimental animals for this study. Mice in the experimental group were infected with $0.2 \mathrm{ml}$ of $P$. berghei parasitee by obtaining parasitized blood (3-4 drops) from the cut tail tip of the infected mice (donor) as described by David et al., (2010) which contains about twelve thousand (12000) parasites.

\subsection{Determination of parasitaemia}

Parasitemia was confirmed by preparing a thin blood film from blood obtained from the cut tail of the infected mice and stained with Giesma stain to be viewed under the light microscope. Determination of the parasitemia was done by counting at least three fields per slide with 200 total white blood cells (TWBC) per field [10].

Parasites $/ \mu \mathrm{L}$ of blood $=$ No. of parasites $\mathrm{x}$ TWBC count $/ \mu \mathrm{L}$

$$
200 \text { (total leucocytes counted) }
$$

\subsection{Drug Preparation and Administration}

\subsubsection{Coartem}

The antimalaria drug Coartem (Artemether and Lumefantrine) was obtained from Ehicare Pharmacy in Ekpoma, Edo State. Six (6) tablets containing $80 / 480 \mathrm{mg} / \mathrm{kg}$ of active ingredient was mesh into powder form and were further homogenized in $150 \mathrm{ml}$ of distilled water (H20). The homogenized mixture was then allowed to stand for 24 hours after a series of periodic stirring. The mixture was collected in a clean container and preserved in a refrigerator at minimum cool temperature. About $56 \mathrm{mg} / \mathrm{kg}(0.25 \mathrm{ml})$ of Artemether / Lumefantrine was given morning and evening orally between 8:00am and 4:00pm for 7 days with the aid of an orogastric canula.

\subsection{Determination of Weight}

Animal weights were measured in grams (g) using an electronic weighing scale (Cardinal Scale Manufacturing Co., Webb City, MO).

\subsection{Sacrifice and Tissue Extraction}

Twelve (12) hours following the last treatment, the animals (per group) were re-weighed and immediately sacrificed via cervical dislocation. Thereafter, the kidney was carefully removed and some fixed in $10 \%$ formal-saline for histological technique after the method of Kurman et al., (2009).

\subsection{Histological Study}

Harvested kidney tissues were dehydrated in an ascending grade of alcohol (ethanol), cleared in xylene and embedded in paraffin wax. Serial sections of 7 microns thick were obtained using a rotatory microtome. Deparaffinised sections were then stained routinely with Hematoxylin and Eosin [H \& E]. Photomicrographs of the results were obtained using research photographic microscope in the Department of Anatomy, Faculty of Basic Medical Sciences, Ambrose Alli University, Ekpoma, Edo State, Nigeria. 


\subsection{Ethical Approval}

Ethical approval was sought from the Research and Ethics Committee of the College of Medicine, Ambrose Alli University, Ekpoma, Edo State.

\subsection{Statistical Analysis}

For each group, body weight changes were noted within test duration and compared between groups with the one way analysis of variance. Where differences exist, the tukey (Post Hoc) test was used to ascertain the cause of the differences in body weight due to P. berghei. Statistics was carried out with a Graph pad prism software (version 8). A p-level less than 0.05 was considered as statistically significant.

\section{Results and discussion}

For decades now, the control of malaria has been a major challenge in the world due to increasing resistance of $P$. falciparum to anti-malaria drugs, particularly chloroquine and sulfadoxine pyrimethamine therapy, with reduced efficacy of chloroquine in the treatment of uncomplicated malaria since late 1990s [11]. This has led to sweeping changes in antimalaria treatment recommendations [12], with worsening damage to affected body organs/systems. This has led the National Malaria Control Programme to recommend the use of Artemisinin-based combination therapy (ACTs) for the treatment of uncomplicated malaria in 2005. For several reasons as increased effectiveness, low resistance, few side effects and/or high tolerance (Tshefu et al., 2010). Till this day, the use of different brands of ACTs has become very popular [13], warranting the need for research-based verification of tissue/organ recovery due to ACT treatment as a result of damage(s) due to malaria parasite.

In this study, we investigated the effect of malaria parasitemia on the histology of the kidney and body weight changes in coartem (anti-malaria) treated and non-treated mice. From our observations, the body weight of changes of $P$. berghei infested, untreated mice showed a statistically insignificant decrease ( $p>0.05)$ compared to control (normal) mice group. The same goes for P. berghei infested, coartem treated group; even though this increased insignificantly (figure 1).

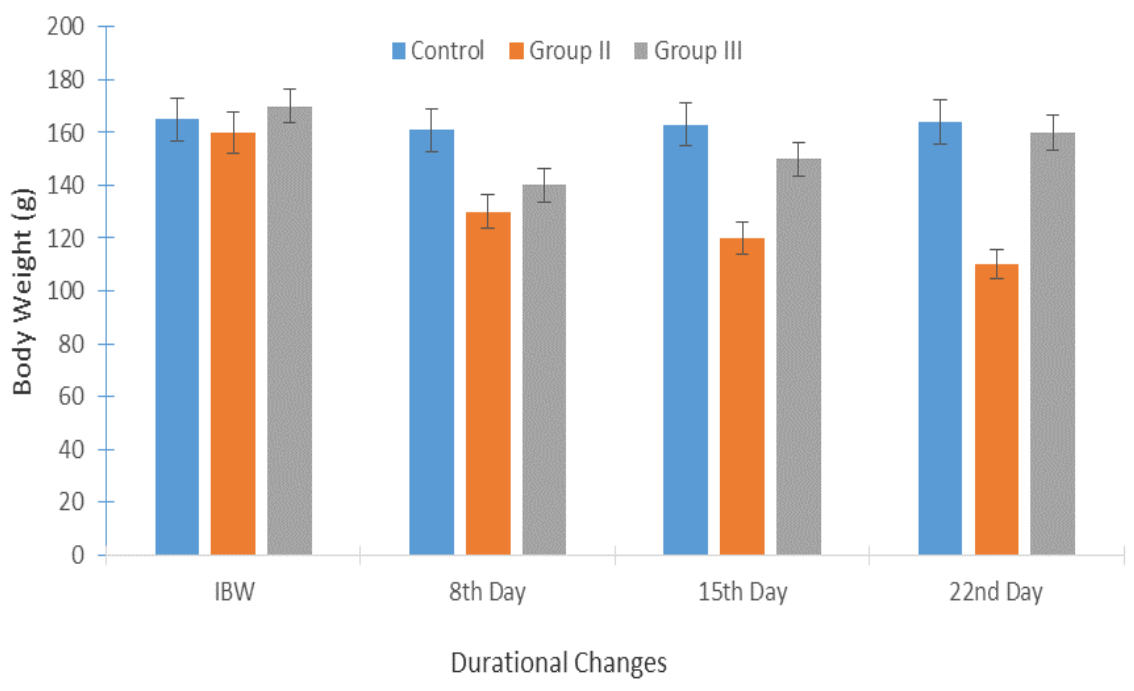

Figure I Effects of P. berghei Induced Malaria on Body Weights

Notable from above chart (figure I) is the relative decrease $(\mathrm{p}<0.05)$ in body weight of group II animals as against others. This decreased was apparently significant across board as against the body weight of control group. 


\section{Plate I}

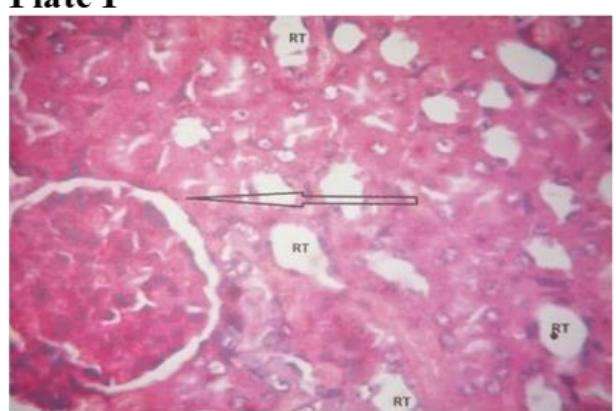

Control Kidney showing Renal tubule (RT) $X 400 H$ and $E$

\section{Plate III}

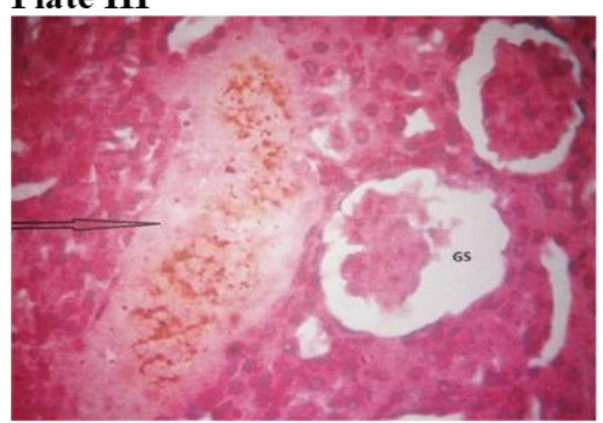

Infected Kidney showing

Glomerulosclerosis (GS)

(RT) $X 400 H$ and $E$

\section{Plate V}

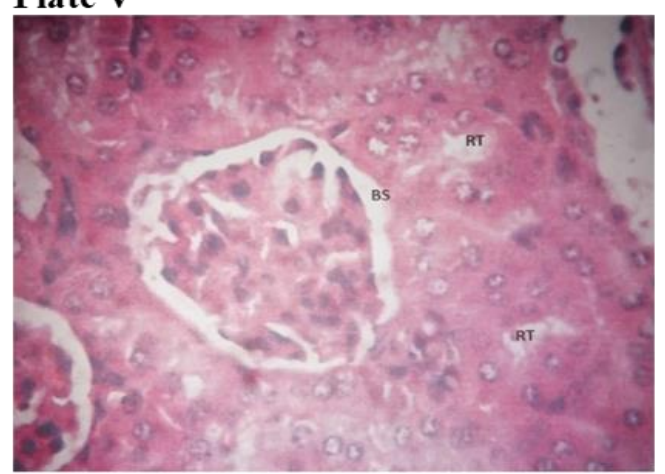

Coartem treated kidney showing marked

Improvement in renal tissue

\section{Plate II}

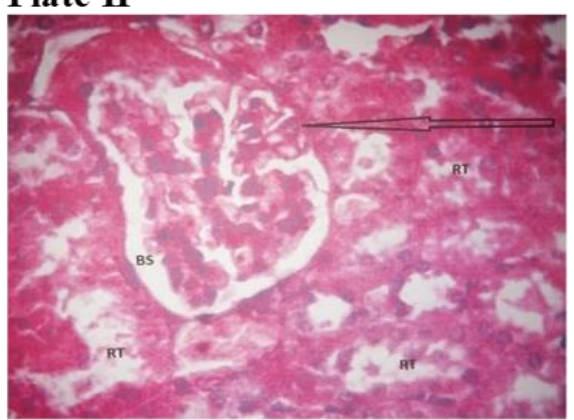

Control Kidney showing Bowman space (BS) $X 400 H$ and $E$

\section{Plate IV}

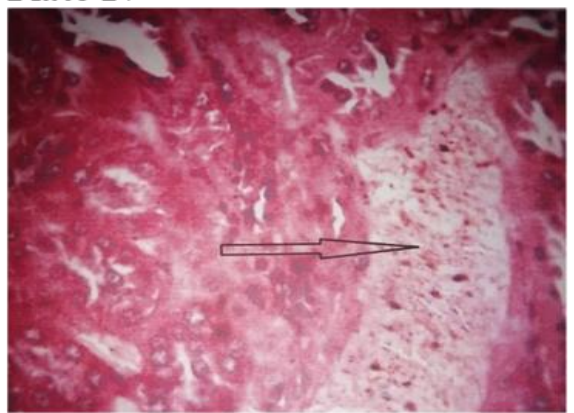

Infected Kidney showing

Congested vessles (GS)

Figure 2 Micrograph Showing the Effects of Malaria Parasitemia on the Kidney

Figure 2 (above) comprised of histo-micrographs of the kidneys for different treatment groups (Plates I - V). here,treatment with Coartem (Anti-malaria) showed a remarkable improvement in selected areas of the renal tubule, whereas, Malaria Infected Kidney showed Glomerulosclerosis (GS) and congestions of varying degrees

In this study also, histological examination of the tissue section from untreated mice revealed normal tubules and bowman's space around the glomerulus of the nephron, with a characteristic mild interstitial oedema and presence of polymorphonuclear cells, severe glomerulosclerosis, interstitial oedema and congested blood vessels. These observed lesions were consistent with the earlier findings of Patna (2016) who observed that clinical course malaria was consistent with acute tubular necrosis in majority of the patients, with one out of six revealing histological features of necrotizing glomerulonephritis along with acute tubule-intestinal nephritis. This study is also consistent with the findings of Danladi et al., (2013) who observed that histological examination of the tissue section from mice administered ACT showed moderate to severe glomerular degeneration, focal haemorrhage, oedema, congested blood vessels, cloudy swelling and degenerative changes of the tubules. Hence, it can be deduced from current study that 
malaria parasitemia affects histology of the kidney in mice. In this study also, coartem may have acted as antimalarial agent in restoring normal histological features of the kidney in treated mice.

\section{Conclusion}

This study has demonstrated that mice infested with $P$. berghei show an insignificant decrease in body weight as against non-infested (control) mice. Study also observed that malaria parasitemia affects the renal blood vessels, glomerulus and interstitial histo-architecture of the kidney in infested mice with a characteristic mild interstitial oedema and presence of polymorphonuclear cells. Thus, malaria parasitemia adversely affects the kidney.

\section{Compliance with ethical standards}

\section{Acknowledgments}

We acknowledge the efforts of the authors and the laboratory technologists who participated in one way or the other towards the success of this study.

\section{Disclosure of conflict of interest}

All authors declare no conflict of interest.

\section{Statement of ethical approval}

Ethical approval was sought from the Research and Ethics Committee of the College of Medicine, Ambrose Alli University, Ekpoma, Edo State.

\section{References}

[1] Barsoum RS. Malarial acute renal failure. J Am Soc Nephrol. 2000; 11: 2147-2154.

[2] Kute VB, Trivedi HL, Vanikar AV, Shah PR, Gumber MR, Patel HV. Plasmodium vivax malaria-associated acute kidney injury, India, 2010-2011. Emerg Infect Dis. 2012; 18: 842-845.

[3] Saravu K, Rishikesh K, Parikh CR. Risk factors and outcomes stratified by severity of acute kidney injury in Malaria. 2014; 9:e90419.

[4] Elsheikha HM, Sheashaa HA. Epidemiology, pathophysiology, management and outcome of renal dysfunction associated with plasmodia infection. Parasitol Res. 2007; 101: 1183-1190.

[5] Susan LP, Indra N, Richard C. The phylogeny of rodent malaria parasites: Simultaneous analysis across three genomes;Infection, Genetics and Evolution. 2007; 7(1): 74-83.

[6] Taub D, Hoffsommer RD, Slates HL, Wendler NL. 16ß-Methyl cortical steroids". Journal of the American Chemical Society. 1958; 80(16): 44-35.

[7] Thiam S, Thior M, Faye B, Ndiop M, Diouf ML, Diouf MB, Diallo I, Ba F, Ndiaye JL, Albertini A, Lee E, Jorgensen, P, Gaye 0, Bell D. Major reduction in anti-malaria drug consumption in senegal after nation-wide introduction of malaria rapid diagnostic tests. PLoS One. 2011; 6: 4.

[8] White NJ. Assessment of the pharmacodynamic properties of antimalaria drugs in vivo. Antimicrobial Agents and Chemotherapy. 1997; 41: 1413-1422.

[9] Neena V, Sunita B, Sadhna M, Sukla B, Aditya P. Congenial malaria with a typical presentation: A case report from low transmission area in India. Malaria J. 2007; 6: 43-48.

[10] Zucker JR, Campbell CC. Malaria. Principles of prevention and treatment. Infect. Dis. 1993; 7(3): 547-567.

[11] Pascual A, Madamet M, Bertaux L, Amalvict R, Benoit N, Travers D. In vitro piperaquine susceptibility is not associated with the Plasmodium falciparum chloroquine resistance transporter gene. Malar J. 2013; $12: 431$.

[12] Attaran A, Barnes KI, Curtis C, d'Alessandro U, Fanello CI, Galinski MR. WHO, the Global Fund, and medical malpractice in malaria treatment. Lancet. 2004; 363(9404): 237-40.

[13] Obianime AW, Aprioku JS. Mechanism of action of artemisinin on biochemical, hematological and reproductive parameters in male guinea pigs. Int J Pharmacol. 2011; 7: 84-95. 